\title{
ASÍ EN LA TIERRA COMO EN EL CIELO. CONSIDERACIONES SOBRE LA DEMONOLOGÍA CRISTIANA TARDOMEDIEVAL A PARTIR DEL LIBER QUINTUS DEL FORTALITIUM FIDEI
}

\author{
POR \\ Constanza CAVAlLERo \\ Universidad de Buenos Aires / CONICET \\ cony.cavallero@gmail.com
}

RESUMEN

El presente trabajo explora el lazo existente entre el discurso demonológico expresado por fray Alonso de Espina en el Liber quintus de su Fortalitium fidei (escrito c. 1460) y las principales inquietudes que manifiesta el fraile a lo largo de su obra. Sus disquisiciones demonológicas le permiten vincular el mundo sensible y suprasensible (sobre todo, ante quienes descreían del "más allá") y enfatizar la injerencia del plano trascendente en el destino de los cristianos, tanto a nivel comunitario como individual, instigando, por esa vía, la conversión verdadera y la reforma de costumbres.

PALABRAS ClAVE: Demonología, el "más allá", descreencia, reforma de costumbres.

\section{ON EARTH AS IT IS IN HEAVEN. \\ CONSIDERATIONS ON CHRISTIAN DEMONOLOGY IN THE LATE MIDDLE AGES BASED ON THE LIBER QUINTUS OF THE FORTALITIUM FIDEI}

\begin{abstract}
This work explores the relationship between the demonological discourse provided by Alonso de Espina in the Liber quintus of his Fortalitium fidei (written c. 1460) and the main concerns expressed by the friar throughout his work. His demonological disquisitions allow him to link the visible and invisible world (especially, vis-à-vis those who did not believe in the Beyond) and place emphasis on the influence of the transcendental plane on Christians' fate, both at collective and at individual levels, thus instigating true conversion and a change in customary practices.
\end{abstract}

KEY WORDS: Demonology, the Beyond, disbelief, reform of habits.

Recibido/Received 04-04-2014

Aceptado/Accepted 27-05-2015

Sería atinado incluir el Liber quintus del Fortalitium fidei de fray Alonso de Espina, titulado "De bello demonum" (c. 1460), entre los escritos fundadores de la demonología moderna en suelo hispano. ${ }^{1}$ La importancia innegable de dicho libro radica, en primer lugar, en la gran popularidad que alcanzó la voluminosa obra del frai-

1 Utilizo en el presente trabajo el más temprano manuscrito latino conservado del Fortalitium fidei, que data de 1464, conservado en el archivo de la Catedral de Burgo de Osma, códice $n^{\circ} 154$. He cotejado el manuscrito con las diversas ediciones incunables de la obra: la de Johannes Mentelin (Estrasburgo, 1471), la de Guillelmus Balsarin (Lyon, 1487), las de Antonius Koberger (Nuremberg, 1485 y 1494), la de Johannes de Romoys (Lyon, 1511) y la de Johannes Moylin (París, 1525). le castellano en los siglos XV y XVI. ${ }^{2}$ En segundo término, en el hecho de que dicho libro constituye el primer tratado llevado a la imprenta que discurre sobre el fenómeno brujeril, apremiante en la cristiandad latina desde mediados del siglo xv. En tercer lugar, la incorporación misma de un libro sobre demonios, creaturas inmateriales, dentro de un tratado, como el Fortalitium, consagrado fundamentalmente a lidiar con los adversarios corpóreos y

2 Clark, S. 2001. "Brujería e imaginación histórica. Nuevas interpretaciones de la demonología en la Edad Moderna" en M. Tausiet y J. Amelang (eds.), El diablo en la Edad Moderna: 43. Madrid: Marcial Pons; Meyuhas Ginio, A. 1998. La forteresse de la foi. La vision du monde d'Alonso de Espina, moine espagnol (?-1466): 10. Paris: Cerf. 
humanos de la ecclesia (herejes, judíos y sarracenos) resulta una originalidad insoslayable de la obra de Espina. Por estos motivos, el Liber quintus constituye una valiosa puerta de entrada al estudio de la demonología ibérica en los albores de la Modernidad.

En consideración de lo dicho, resulta llamativo que el mencionado libro no haya recibido aún suficiente atención por parte de los estudiosos de la materia. ${ }^{3}$ El presente estudio pretende adentrarse en este terreno inexplorado por la historiografía especializada, atendiendo al lazo existente entre la postura de Alonso de Espina en materia demonológica y las principales preocupaciones y temáticas que atraviesan el Fortalitium desde el proemio hasta sus últimas líneas. La incorporación de un libro exclusivamente demonológico dentro de un tratado que forma parte de la literatura polémica cristiana sólo puede ser comprendida cabalmente, en mi opinión, a la luz de la totalidad del discurso adversus inimicos del que forma parte y de la funcionalidad que cobra la demonología dentro del derrotero discursivo que ha puesto por escrito este predicador popular a mediados del siglo XV.

\section{LA GUERRA DE LOS DEMONIOS}

El campo historiográfico sobre la materia ha hecho énfasis en el carácter moderado de la demonología ibérica. En contraste con la demonología moderna extrapirenaica, se ha destacado la cautela de los teólogos, obispos e inquisidores peninsulares en materia brujeril ${ }^{4}$. Dos factores

3 Sobre el Liber quintus del Fortalitium fidei, véase Meyuhas Ginio, A. 1990. "The conversos and the magic arts in Alonso de Espina's Fortalitium Fidei". Mediterranean Historical Review 5, 2: 169-182 y Meyuhas Ginio, A. 1998: 169-180. Respecto del tratado de Espina en general, véase Echevarría, A. 1999. The fortress of faith: the attitude towards Muslims in fifteenth century Spain, Leiden-Boston-Koln: Brill; McMichael, S. 2007. "Friar Alonso de Espina, Prayer, and Medieval Jewish, Muslim and Christian Polemical Literature", en T. Johnson (ed.). Franciscans at Prayer: 271-304. Leiden-Boston: Brill; Monsalvo Antón, J. M. 2013. "Ideología y anfibología antijudías en la obra Fortalitium Fidei de Alonso de Espina. Un apunte metodológico", en P. de la Cruz Díaz Corral et alii. (eds.). El historiador y la sociedad: homenaje al profesor José María Mínguez: 163-188.Salamanca: Ediciones Universidad de Salamanca; Vidal Doval, R. 2013. Misera Hispania: Jews and Conversos in Alonso de Espina's Fortalitium fidei. Oxford: The Society for the Study of Medieval Languages and Literature; Cavallero, C. 2014. "En los confines del relato cristiano: los pliegues del antijudaísmo en el Fortalitium fidei de Alonso de Espina (Castilla, siglo Xv)", en A. Guiance (ed.), Legendario cristiano: creencias y espiritualidad en el pensamiento medieval: 53-101. Buenos Aires: CONICET - Instituto Multidisciplinario de Historia y Ciencias Humanas.

4 La región noreste de la Península ha sido una excepción en este sentido. Véase sobre este asunto: Knutsen, G. 2010. Servants of Satan and masters of demons: The Spanish Inquisition's Trials for Superstition, Valencia and Barcelona, 1478-1700: 39-50. Turnhout: Brepols; Azurmendi, M. 2013. Las brujas de Zugarramurdi. La historia del aquelarre y la Inquisición. Córdoba: Almuzara; Alcoberro, A. 2014. "The Catalan Church and the Witch Hunt: the Royal Survey of 1621". eHumanista. Journal of Iberian Studies 26: 153-169; Bazán Díaz, I. 2014. "El tratado de Fray Martín de Castañega como remedio contra la superstición y la brujería en la diócesis de Calahorra y La Calzada: ¿un discurso al margen del contexto histórico (1441-1529)?". eHumanista. Journal of Iberian Studies 26: 18-53; Castell Granados, P. 2014. "Wine vat witches suffocate children. The Mythical Components of the Iberian Witch". eHumanista. Journal of Iberian Studies 26: 170-195. explicativos medulares han sido blandidos para dar cuenta de esta cualidad idiosincrática del ámbito ibérico: (a) el peso de la presencia de conversos y minorías culturales al interior de la sociedad cristiana y (b) la importancia de la injerencia inquisitorial en los casos de presunta brujería. Respecto del primer elemento mencionado, se suele aducir que la acuciante "cuestión conversa", en particular, dificultó la radicalización del discurso demonológico cristiano y la propagación de la caza de brujas. ${ }^{5}$ En cuanto al segundo elemento, se ha considerado, ajustadamente, que la presencia de tribunales inquisitoriales modernos en suelo hispano (instaurados, justamente, con el fin de acabar con la pretendida amenaza de la "herejía conversa") habría entorpecido la escalada de violencia que protagonizó el discurso demonológico en el corazón de Europa y la praxis represiva que ella acarreó. Signada por su carácter centralizado y pregonando una actitud escéptica hacia la brujería, una práctica comedida de la tortura y cierta hostilidad hacia las persecuciones masivas, la Inquisición resultó, de hecho, una protagonista fundamental de la prudencia que caracterizó a la alta cultura teologal de origen hispano. ${ }^{6}$ La falta de sintonía, en el plano del discurso demonológico, entre la Península y el corazón de Europa resulta evidente, en lo que respecta al siglo $\mathrm{XV}$, al contrastar el rol que cumplieron tratados como el Formicarius de Johannes Nider o el Malleus maleficarum de Heinrich Krämer en la justificación y aliento de la praxis

5 Ver al respecto Trevor-Roper, H. 1969. The European Witch-Craze of the Sixteenth and Seventeenth Centuries, and Other Essays. New York: Harper \& Row (edición castellana: 2009. La crisis del siglo XVII. Religión, Reforma y cambio social: 120. Buenos Aires: Katz); Levack, B. 1995. The Witch-Hunt in Early Modern Europe. London: Longman (edición castellana: 1995. La caza de brujas en la Europa moderna (trad. J. Aristu): 229-230. Madrid: Alianza); Kamen, H. 2006. “Spain”, en R. Golden (ed.), Encyclopedia of witchcraft: the Western tradition: 1070. Santa Barbara: ABC-Clío; Delumeau, J. 1978. La Peur en Occidente aux $X I V^{e}$ et XVIII siècles. Une cité assiégée. Paris: Fayard (edición castellana: 2002. El miedo en Occidente (Siglos XIV-XVIII). Una ciudad sitiada (trad. M. Armiño): 602. Madrid: Taurus); Haliczer, S. 1991. "The Jew As Witch: Displaced Aggression and the Myth of the Santo Niño de La Guardia”, en M. Perry y A. Cruz (eds.), Cultural Encounters. The Impact of the Inquisition in Spain and the New World: 146-156. Berkeley: University of California Press. Una postura divergente presenta Henningsen (Henningsen, G. 2003. "La Inquisición y las brujas", en A. Borromeo (ed.), L'Inquisizione, atti del Simposio internazionale Citta del Vaticano, 29-31 ottobre 1998: 583. Citta del Vaticano: Biblioteca Apostólica Vaticana). Por otra parte, una variante de la postura que sopesa la presencia de minorías culturales al interior del cristianismo pero que, no obstante, deja de lado la teoría del "chivo expiatorio" para explicar la ausencia del fenómeno brujeril en la mitad sur de España (ponderando, en su lugar, la noción de "cosmologías incompatibles") es la postulada por Knutsen (Knutsen, G. 2010: 39-50).

6 Véase Henningsen, G. 2003: 583 y ss.; Monter, E. W. 1983. Ritual, Myth and Magic in Early Modern Europe: 67 Brighton: Harvester Press; Monter, E. W. 2013. "Witchcraft in Iberia", en B. Levack (ed.), The Oxford Handbook of Witchcraft in Early Modern Europe and Colonial America: 268-282. Oxford: Oxford University Press; Levack, B., 1995: 283-287; Pérez, J. 2010. Historia de la brujería en España: 235-280. Madrid: Espasa; Muchembled, R. 2006. "Foreword”, en R. Golden (ed.), Encyclopedia of witchcraft: 492-498, XXVII; Verdon, J. 2008. Les superstitions : 265. Paris: Perrin; Campagne, F. 2002. Homo catholicus. Homo superstitiosus. El discurso antisupersticioso en la España de los siglos xV a XVIII: 462. Madrid: Miño y Dávila; Knutsen, G. 2010: 51-81. Un rol semejante habría cumplido la Inquisición romana en la Península Itálica. Véase Martin, R. 1989. Witchcraft and the Inquisition in Venice, 15501650: 246 y ss. Nueva York-Oxford: Blackwell. 
represiva con la postura escéptica sostenida por personajes como Lope de Barrientos, Alonso de Espina mismo o Martín de Arlés. ${ }^{7}$

El presente estudio del Liber quintus del Fortalitium fidei no cuestionará el consenso historiográfico respecto de la moderación demonológica hispana. Más bien, propone dejar a un lado, por un momento, la lógica dicotómica que parte del binomio radicalidad/moderación para comprender la demonología temprano-moderna y, en vez de ello, pensar ciertas aristas fundamentales del discurso demonológico del monje castellano a la luz de las inquietudes y opiniones medulares manifestadas a lo largo del Fortalitium fidei mismo. Considero que la demonología del franciscano debe ser estudiada desde una perspectiva holística, es decir, sin desconocer la importancia de la cuestión brujeril pero partiendo de una visión más amplia y compleja del discurso demonológico. Stuart Clark ha definido la demonología como "las creencias relativas a los aspectos demoníacos de la brujería y otras prácticas prohibidas por el cristianismo medieval y de la Edad Moderna" y "las demonologías" como "tratados formales (...) que exploraban y debatían las complejidades de la brujería y otros temas afines de un modo sistemático y teórico, aportando una orientación sobre qué creer y qué no en relación con aquéllos". ${ }^{8}$ En ambas definiciones la brujería emerge como el aspecto central y definitorio de la demonología. En este punto no acuerdo con Clark y el Liber quintus de Espina muestra que difícilmente tales definiciones sean exactas: la brujería aparece tratada allí sólo en uno de los nueve puntos de una de las doce considerationes que lo conforman.

\section{ALCANCE Y SIGNIFICACIÓN DEL LIBER QUINTUS}

No hay duda de que la presencia de minorías culturales en la Península, sobre todo de judíos y judeoconversos, moldeó en gran medida los contornos particulares del discurso sobre el demonio de Alonso de Espina en particular y de los teólogos hispanos en general. La presencia de judíos

\footnotetext{
7 Para una comparación entre el discurso demonológico de Lope de Barrientos y el de Johannes Nider véase Cavallero, C. 2011. "Brujería, superstición y 'cuestión conversa'. Historias de construcción de 'otroscristianos'". Anuario de Estudios Medievales 41,1: 343-373. Las fuentes citadas pueden ser consultadas por las siguientes ediciones: Nider, J. 2005. Les sorciers et leurs tromperies (La fourmilière, livre V). Grenoble: J. Million; Kramer, H. y Sprenger, J. 2006. Malleus maléficarum. El martillo de los brujos. El libro infame de la Inquisición (trad. Del inglés E. D’Elio). Barcelona-México: Reditar; Lope de Barrientos, 2000. Tratado de Caso y Fortuna, Tratado del Dormir y Despertar y Tratado de las especies de adivinanzas, en F. Álvarez López, Arte mágica y hechicería medieval. Tres tratados de magia en la corte de Juan II. Valladolid: Diputación de Valladolid; Fernández de Madrigal, A, Commentaria super Genesim (Venetiis, 1507) y, del mismo autor, In quinquem prima capitula beati Matthei explanatio (Venetiis, 1506); Arlés y Andosilla, M. 1971, De superstitionibus, en G. Gaztambide, "El tratado 'De superstitionibus' de Martín de Andosilla". Cuadernos de Etnología y Etnografía de Navarra III: 249-322; Basín, B., Tractatus exquissitimus de magicis artibus et magorum maleficiis (París, 1483). Esta última fuente ha sido editada en castellano como Basín, B. 1988. "Tratado notable de las artes mágicas y maleficios de los magos", en M. Jiménez Monteserín (ed.), "De brujos y teólogos. Cultura popular y mundo mágico”, Áreas 9: 170-182.

8 Clark, S. 2001:. 22.
}

al interior de la sociedad cristiana, la "herejía conversa" e incluso la guerra contra el moro resultan factores insoslayables a tener en cuenta. ${ }^{9}$ Con todo, me gustaría poner el foco, en el presente trabajo, en otros sentidos en los cuales la demonología que presenta Alonso de Espina se vincula con los diversos frentes de guerra que, a ojos del fraile, azotaban la fortaleza de la fe y con su modo particular de comprender dichos ataques. Los apartados desplegados a continuación permitirán dilucidar, también, por qué Espina, pese a confiar de antemano en la derrota absoluta de los ángeles caídos ("demones perdiderant potestatem... et eorum princeps victus et ligatus usque ad prefinitum tempus sit in inferno"), dedica a los demonios un libro particular en su obra de polémica interreligiosa y defensa de la fe. ${ }^{10}$

\section{a. Historia y suprahistoria, inmanencia y trascendencia.}

El discurso sobre el demonio que presenta el fraile castellano permite situar dentro de la filosofía (o teología) de la historia cristiana los ataques que, a ojos de Espina, sufría perceptiblemente la ecclesia desde distintos flancos a mediados del siglo XV. Las embestidas perpetradas por los adversarios corporales de la fe emergen como diversos avatares de la guerra del demonio contra el hombre (permitida, en toda ocasión, por la divinidad). ${ }^{11}$ Por lo tanto, son interpretadas, también, como hitos providenciales de la historia de la salvación: los duros combates que sufría la ecclesia en sus tiempos, frágil en razón de la proximidad de los tiempos apocalípticos, cobraban sentido dentro del plan diseñado por la divinidad para triunfar sobre el demonio.

Desde el prisma del cristianismo, la historia de la humanidad no estaba definida por una rectilínea sucesión de hechos sino por un plan providencial marcado a fuego por el gran "acontecimiento sin fin". ${ }^{12}$ En este sentido, resulta interesante definir la concepción cristiana de la historia para mejor entenderla- a partir de la distinción de Walter Benjamin entre la filosofía de la historia que opera a través de un procedimiento de adición (la que "proporciona una masa de hechos para llenar el tiempo homogéneo y vacío") y aquella otra según la cual "el pensamiento se detiene de golpe en una constelación cargada de tensiones". El primer modelo, caracterizado por la sucesión continua de hechos, es llamado 'historicismo'; el segundo, denominado 'monádico', preconiza un evento único, de cariz mesiánico, que

9 Véase Cavallero, C. 2012. "A facie inimici: la dimensión política de la demonología cristiana en el Fortalitium Fidei de Alonso de Espina (Castilla, siglo XV)". Edad Media. Revista de Historia 13: 209-239.

10 Fortalitium fidei, Liber quintus, Consideratio IX: f. 181r.

11 “...[dyabolus] excitavit contra eam [civitatem Dei] persecucionem gentilium, que duravit toto tempore apostolorum et ducentis annis ultra (...). In quo bello nichil lucratus est dyabolus sed pocius miserabiliter victus ab illo bello cessavit, cum per talem persecucionem plus multiplicarentur fideles et forcior efficiebatur civitas iustificationis vere fidei et bone consciencie. Suscitavit etiam bellum hereticorum, quorum hereses per diversa concilia examinate dampnate sunt et plurimi eorum ignibus cremati, sic quod eorum in publico non est vox nec sonus, licet in occulto nimium seviat ista pestis" (Fortalitium fidei, Liber quintus, Consideratio IX: f. 181v.)

12 Boureau, A. 1993. L'événement sans fin. Récit et christianisme au Moyen Age. Paris: Les Belles Lettres. 
irrumpe en el continuum del tiempo histórico e ilumina en un solo instante el devenir de la historia toda. ${ }^{13}$ En tiempos de Espina, esta segunda forma de leer la historia era hegemónica y permeaba el modo de comprender el pasado y el presente y de afrontar el futuro: la vida terrenal del JesúsMesías era ese acontecimiento que dio vuelta el tablero de la historia y la condensó, cristalizó o resumió en una "mónada". Este acontecimiento definitivo en la filosofía de la historia del cristianismo fue, en este sentido, el punto culmen de unión entre la temporalidad y la eternidad, es decir, entre la historia terrenal y el plano de lo transcendente que la dotaba de sentido.

El discurso demonológico se adecua al deseo del fraile de mostrar que, en el devenir de la historia terrenal, marcado a fuego por aquel acontecimiento dador de sentido, las inteligencias separadas son actores de relevancia. Espina narra la historia de la oposición entre el bien y el mal desde el cielo empíreo -es decir, desde la guerra entre ángeles buenos y malos- hasta los últimos tiempos (considerationes III, VI y IX del Liber quintus). En ambos extremos de la historia, el demonio aparece como protagonista y, entre uno y otro, opera como ideólogo y autor de las "mil formas de dañar" que acompañaron, en gran medida, la sucesión de caídas del hombre en el pecado a lo largo del tiempo. ${ }^{14}$ La continuidad entre la guerra del cielo y la guerra en la Tierra resulta evidente cuando, siguiendo a Mayronis, Espina sostiene que Lucifer impelió a los ángeles a consentirlo en su rebelión del mismo modo en que luego, desterrado del cielo, impelería a los hombres a caer en el pecado ("sicut enim nunc impellit homines ad peccandum sic et tunc impullit sanctos angelos ad consenciendum sibi, sed viriliter resisterunt"). ${ }^{15}$ Asimismo, el fraile afirma que, así como demonios y ángeles habían combatido en el cielo, los espíritus angélicos continuaban batallando, también, en el mundo terrenal, intentando proteger o dañar a los hombres. En opinión de Espina, la malicia de los demonios era menguada por la resistencia que oponían los ángeles custodios: "habet enim anima duos $^{16}$ angelos, unum bonum ad custodiam et aliud malum ad exercicium". ${ }^{17}$

Además, como se lee en los diversos libri del Fortalitium, los demonios eran quienes lideraban los ataques de los diversos enemigos corpóreos de la ecclesia. Éstos poseían como denominador común su lazo con el diablo y sus acciones formaban parte de las pluriseculares estrategias diabólicas para luchar contra los hombres que permanecían firmes en la fe. ${ }^{18}$ Así pues, como afirma el fraile hacia el final de la consideratio $\mathrm{V}$, un único demonio era el príncipe de los demás demonios y, también, de los hombres malignos ("non solum unus demon est princeps aliorum demonum

13 Mates, R. 1991. La razón de los vencidos: 183-184. Barcelona: Anthropos; Benjamin, W. 1971. Zur Kritik der Gewalt und andere Aufsätze. Frankfurt am Main: Suhrkamp. Edición en castellano: 1978. Para una crítica de la violencia (trad. M. A. Sandoval): 138 y ss. México: Premiá.

14 Liber quintus, Consideratio VI: f. 179v.

15 Liber quintus, Consideratio III: f. 177r.

16 anima duos om. edd.

17 Fortalitium fidei, Liber quintus, Consideratio VIII; f. 181r.

18 Véase al respecto Cavallero, C. 2012. sed etiam malorum hominum"); por este motivo -agrega el fraile- el demonio había sido llamado en el Evangelio "princeps huius mundi", porque dominaba también a los hombres que se sometían a él a causa del pecado. ${ }^{19}$ Resulta patente, a partir de lo dicho, que, en el discurso de Espina, la demonología constituye un elemento fundamental para dar cuenta del permanente engarce de la historia terrenal (con sus tantas guerras) en la suprahistoria (con su macroguerra) y, también, para reunir el mundo de la materia con el plano de la trascendencia. Dado que estos variados inimici fidei eran hijos o servidores del diablo (ministro, a su vez, de la divinidad), sus ataques conformaban, en última instancia, medios a disposición de la misma divinidad para castigar a los pecadores y probar o robustecer la fe de los justos, de modo que se manifestara la voluntad divina en la Tierra y se lograra en ella el cumplimiento absoluto del plan providencial. Ángeles y demonios, en pocas palabras, eran intermediarios entre dos planos que Espina se ocupa de engarzar constantemente: el providencial y el histórico, el material y el espiritual, el cielo y la Tierra.

Por otra parte, la demonología de Espina resulta útil, también, para remarcar el valor inconmensurable que adquiere el ya mencionado "acontecimiento sin fin". Es la maldad del demonio y su magno poder sobre los hombres lo que resulta clave para comprender -siguiendo la argumentación del fraile- la urgencia de la Venida de Cristo, es decir, para comprender el valor de la "mónada" que condensaría el devenir de la historia toda. Alonso de Espina sostiene que Dios decidió entregar a su Hijo previendo cuán asolada estaría la Ciudad de la Justificación por los demonios y cuántas almas se condenarían:

Hanc desolacionem previdens Salvator noster, dolens de talium animarum dampnatione, suo sanguine redempturum flevit super illam, scilicet, civitatem iustificationis, quasi ei diceret: " $O$, civitas mea dilecta, o spiritualis habitacio mea, quis te sic destruxit, quis te sic in abissum mersit? $O$, civitas, melius tibi fuisset nunquam fuisse! Ubi sunt muri caritatis, ubi est antemurale iusticie, ubi est fossatum humilitatis? Ubi sunt tui prelati caritativi, ubi principes iusti, ubi sunt humiles religiosi? Omnia submersa sunt». ${ }^{20}$

La sangre derramada de Cristo fue lo que salvó a la ciudad amada de la servidumbre del demonio. Éste, aun vencido y atado por mil años, continuaría interviniendo, de allí en más, en la medida en que le fuera permitido, de forma tal que desempeñara en todo momento el rol que Dios le dio

19 Fortalitium fidei, Liber quintus, Consideratio V: f. 179r. El lazo entre el mundo de los ángeles y el mundo de los hombres resulta también patente en un pasaje soteriológico ya aludido que incluye el fraile en su Liber quintus: me refiero al locus en el cual el franciscano vincula de modo directo el número de ángeles caídos del cielo tras la guerra empírea con el número de los hombres que habían de ser salvados. Vimos que Espina señala la existencia de dos posturas al respecto: la agustiniana, según la cual se salvarían tantos hombres cuantos demonios cayeron, y la gregoriana, que afirmaba que se salvarían tantos hombres cuantos ángeles permanecieron en el cielo (Liber quintus, Consideratio III: f. 177v.). La relación que existía entre el resultado de la guerra celestial y el resultado de la guerra histórica de los demonios resulta evidente. El Hijo de Dios -agrega luego Espina- había venido a la tierra, justamente, a reunir en Cristo todas las cosas que estaban en el cielo y en la tierra, según lo enseñado en Efesios 1, 10.

20 Liber quintus, Consideratio IX, f. 182v. 
en la historia salvífica del hombre, desde el comienzo hasta el fin de los tiempos. ${ }^{21}$

Es menester comparar la visión de Alonso de Espina, de acuerdo con lo dicho hasta aquí, con la de otro teólogo hispano de la época: Juan de Segovia (1393-1458). Este importante sistematizador de la doctrina conciliar, cronista del cónclave basiliense, dedica la segunda parte de su inacabado Liber de substantia ecclesie, titulada "De angelis", a tratar la cuestión angelológica y demonológica desde una perspectiva eclesiológica. ${ }^{22}$ Allí describe la gran contienda que existió en el cielo entre Lucifer y Miguel, cada uno a la cabeza de ejércitos de ángeles, y presenta ese primer combate como el origen de la Iglesia militante, que luego continuaría su lucha en la Tierra: los hombres se unirían a los ángeles y conformarían la ecclesia que, encabezada por Cristo, resistiría las batallas del demonio y de sus secuaces en la Tierra (es decir, de la "ecclesia malignantium"). ${ }^{23}$ El vínculo entre lo terreno y lo ultraterreno, lo histórico y lo suprahistórico, emerge con claridad en el discurso de Segovia, y el bien y el mal cortan transversalmente ambos planos. Segovia, como Espina, sigue fielmente la noción agustiniana que planteaba la existencia de dos ciudades: una de ángeles y hombres buenos, otra de ángeles y hombres malvados. ${ }^{24}$ Sin duda, en ambos teólogos la impronta agustiniana es muy fuerte: las duo civitates descritas en De civitate Dei (especialmente en los libros XI y XII de la segunda parte) ocupan un lugar de privilegio en el modo en que concebían el mundo $y$, en ambos, el discurso sobre el demonio contribuye a remarcar

21 En este sentido, lo postulado por Espina difería de cristología de su contemporáneo Juan de Segovia: éste recuperó la postura escotista que afirmaba que Cristo habría encarnado aun si el hombre no hubiese caído en el pecado, con el fin de que la humanidad participara de la bienaventuranza (véase Madrigal Terrazas, S. 2000. El proyecto eclesiológico de Juan de Segovia (1393-1458). Estudio del Liber de substantia ecclesiae. Edición y selección de textos: 45. Madrid: Universidad Pontificia Comillas).

22 Véase Madrigal Terrazas, S. 2000.

23 Ibídem: 40, 59.

24 Ibídem: 63. Existe, no obstante, una diferencia entre ambos teólogos: mientras que Espina presenta la guerra en el cielo y la guerra en la Tierra en una suerte de continuidad (el demonio, expulsado del cielo, habría redirigido sus fuerzas a luchar contra el hombre), Segovia tiende a comprender el vínculo entre una y otra esfera desde la alegoría, el paralelismo o, más bien, desde la interpretación especular: el teólogo describe la primera discordia entre ángeles y demonios como el resultado de un cisma ocurrido tras una suerte de concilio general celeste, donde se habría debatido quién sería la cabeza de la ecclesia (Lucifer, soberbio, se habría resistido a aceptar que fuese Cristo, un hombre). Esta interpretación del combate angélico aparecía como arquetipo de la ecclesia terrestre, como patrón ejemplar que hacía directa alusión al cisma acontecido en tiempos de Segovia y de Espina, es decir, el conflicto entre Eugenio IV y el concilio de Basilea. La demonología segoviana, en este sentido, interpretaba la historia de la cristiandad terrenal en virtud de un plano que la trascendía y en el cual ángeles y demonios eran protagonistas. Dicha interpretación le permitía legitimar la postura pro-conciliarista de la cual Segovia fue adalid. Eugenio IV era -en su opinión- nada menos que el papa "luciferino": así como Lucifer se había negado a aceptar la capitalidad de Cristo en el corpus mysticum de la ecclesia, del mismo modo el Papa se oponía entonces a aceptar que la cabeza del corpus politicum fuese el concilio. Ibídem: 41, 57, 68, 72, 74. La equiparación Lucifer-Papa no es caprichosa; es posibilitada por la idea de que la Iglesia terrestre estaba edificada "ad exemplar coelestis hierarchaie" (85). El modo en que Segovia construye esta equiparación es estudiada en Mann, J. 1996, "The Devilish Pope: Eugenius IV as Lucifer in the Later Works of Juan de Segovia". Church History 65, 2: 184-196. la unidad del plano humano y el angélico, del plano corporal con el espiritual, de la historia terrestre y la suprahistoria, el presente y la perspectiva escatológica.

La consideración de la Iglesia celeste como ejemplo y arquetipo de la Iglesia terreste es un denominador común de la eclesiología medieval. ${ }^{25}$ Segovia interpreta de este modo el combate angélico en el cielo, a saber, como patrón ejemplar que hacía directa alusión al conflicto contemporáneo que existía entre Eugenio IV y el concilio de Basilea ${ }^{26}$. La misma relación arquetipo/tipo se cumple en el discurso de Espina, de modo menos directo, entre los fundamentos de la rebelión del ángel en el cielo y los cimientos de la ciudad diabólica en la Tierra: así como el ángel pecó por rechazar a Dios, amándose desordenadamente a sí mismo (es decir, poseyendo Lucifer un "amor inordinatus sui ipsius"), la "ciudad de la destrucción" se edificó también a partir del desprecio de Dios y el amor a sí misma ("incipit a contemptu Dei usque ad amorem sui"). ${ }^{27}$ En cualquier caso, lo interesante es notar que Juan de Segovia y Alonso de Espina, cada uno siguiendo sus propias inquietudes (uno inmerso en la defensa del conciliarismo, otro combatiendo en Castilla a los "enemigos de la fe"), se sirven de la demonología para engarzar los conflictos que percibían en la cristiandad terrena en el plano mayor de la suprahistoria, es decir, del correlato trascendente, espiritual y providencial de los acontecimientos de este mundo.

\section{b. ¿Una refutación de los decreídos?}

En la consideratio décima, Alonso de Espina afirma que los demonios se deleitaban particularmente toda vez que lograban apartar a algún hombre de la fe de Cristo, puesto que, sin esta última, los hombres apenas se ocupaban de cuidar las otras virtudes. Por este motivo, invita a resistir a los demonios con firmeza de fe, citando I Pedro 5: "Sobrii ergo estote et vigilate". ${ }^{28}$ También se preocupa por la fe de los cristianos cuando, discurriendo acerca de la malicia de los demonios, sostiene que muchas veces los demonios persuadían al hombre a realizar un bien pero en pos de que cometiera un mal, como cuando incitaban en alguna persona inestable en el bien la "entrada a la religión", sabiendo de antemano que no permanecería firme sino apostataría ("suadent ingressum religionis scientes quod non permanebunt sed apostatabunt"). Y -dice Espina- también hacían lo opuesto, es decir, desaconsejaban en ocasiones a los hombres rectos a "entrar en la religión" diciendo: "Noli (...) precipitanter agere, diu considera, diligenter intuere. Magnum est quod proponis et opus egens magna

25 Congar, Y. 1968. L'ecclésiologie du haut Moyen Age: 102-127. Paris: Éd. du Cerf.

26 Ver al respecto Wolf, A. M. 2014. Juan de Segovia and the Fight for Peace. Christians and Muslims in the Fifteenth Century: 95-128. Notre Dame: University of Notre Dame Press.

27 Fortalitium fidei, Liber quintus, Consideratio III: f. 177v. y Consideratio IX, f. 181v.

28 Liber quintus, Consideratio X, diff. 9: f. 185r.: “...presertim delectantur demones cum avertunt aliquem a vera fide Ihesu Christi Domini nostri, quia de aliis virtutibus parum curant sine fide. Ideo dicitur primo Petri 5 : Cui resistite fortes in fide. Sobrii ergo estote et vigilate". 
deliberatione, experire quid ${ }^{29}$ possis, amicos consule ne post facta penitere contingat". Ante estas palabras que Bernardo de Claraval, según Espina, ponía en boca del demonio, el cisterciense respondía diciendo que tal opinión era enemiga de la salvación, sofocaba la vida, era madre de la tibieza (mater tepiditatis) y llevaba al vómito. Incitaba, por el contrario, a convertirse a la fe sin duda alguna, sin deliberación previa: "Cum enim verbum Dei esse, non dubites. Quid opus est deliberatione?". ${ }^{30}$ Esta exhortación que incluye el fraile respecto de la necesidad de una inaplazable y vehemente conversión no resulta poco significativa, en absoluto, en la Castilla de mediados del Cuatrocientos.

La preocupación por los hombres sin fe -o débiles en la fe- no es un tema menor para el fraile. Por el contrario, constituye una de sus principales inquietudes, según expresa el Liber secundus, dedicado a la "guerra de los herejes". ${ }^{31}$ En este sentido, cabe pensar que la inclusión de un elaborado discurso demonológico en el Fortalitium fidei no sólo permitía vincular el ataque de los diversos enemigos de la fe dentro del plan trascendental trazado por la divinidad o engarzar el mundo sensible en el suprasensible. Además, y vinculado a ello, la demonología venía a dar cuenta de la descreencia y el titubeo en la fe de muchos cristianos (fundamentalmente conversos) que tanto preocupaban a Espina. En este sentido, el acento en la dimensión trascendente inherente al cristianismo que permitía resaltar la demonología se elevaba frente a la descreencia. Permitía también impugnar la materialidad e inmanencia que asomaban como peligro amenazador en algunas de las herejías asociadas por Espina al mundo converso y por él combatidas en el Liber secundus (como, por ejemplo, la de aquellos que creían "quod nichil aliud erat in hac vita nisi nasci et mori et quod totum aliud vanitas erat", la de quienes afirmaban que no existía el purgatorio o la de quienes negaban "aliam vitam et inmortalitatem anime et resurrectionem"). ${ }^{32}$ La inclusión de un libro demonológico dentro de un tratado de polémica inter (e intra)religiosa como el Fortalitium fidei brindaba, por lo tanto, la ocasión de hacer hincapié en el plano trascendental y en el drama metafísico que enmarcaba la economía cristiana de la salvación y legitimaba un orden que, a ojos de Espina, era asediado dramáticamente en aquellos tiempos.

A la luz de la "cuestión conversa", es posible afirmar que el énfasis en la trascendencia no es un elemento menor en el contexto de la España del siglo xv: careciendo el universo simbólico judío de una dimensión metafísica semejante a la propia del cristianismo (desconocedor, aquel, del "abrumador aparato del infierno y la condena, la caída y la gracia, el

\footnotetext{
${ }^{29}$ Sic ms.: quod edd.

30 Fortalitium Fidei, Liber quintus, Consideratio VIII, f. 181r.

31 Sobre esta cuestión, véase Cavallero, C. 2013. "Judíos, conversos y "malos cristianos" en el Fortalitium fidei de Alonso de Espina: la mirada del Cíclope ante una encrucijada decisiva (Castilla, siglo XV)", en F. Campagne (ed.), Poder y religión en el mundo moderno. La cultura como escenario del conflicto en la Europa de los siglos XV a XVIII: 117162. Buenos Aires: Biblos.

32 Fortalitium fidei, Liber secundus, Consideratio VI, f. 42r. y f. 49r. y v.
}

purgatorio y el juicio final"), ${ }^{33}$ las diversas herejías que eran fruto -a ojos del fraile- del mestizaje cultural y las conversiones masivas, descansaban sobre cierto principio de inmanencia que la demonología cristiana eficazmente venía a refutar. No es casual, en este sentido, que en la primera consideración del Liber quintus, al preguntarse si existían los demonios (an sint), primera pregunta del método escolástico, Espina respondiera que sí argumentando que cristianos, judíos y sarracenos acordaban al respecto..$^{34}$ El fraile sostiene que las Escrituras de los judíos avalaban la existencia de los demonios (por caso, I Reyes 16, 14). También recupera pasajes del Evangelio que daban cuenta de la existencia de esta creencia entre los judíos: en Juan 10, 20, agredían a Cristo acusándolo de tener un demonio y en Mateo 12, 24, decían que Jesús expulsaba demonios en nombre de Belzebú. En opinión de Espina, los judíos no habrían afirmado tales cosas si no creyeran que existían los diablos ("que non afirmarent nisi diabolos crederent essent"). También los sarracenos -dice Espinaconvenían en la existencia de los demonios. ${ }^{35}$ Concluye Espina afirmando que a nadie debía caberle, entonces, duda alguna de la existencia de los demonios y que era necesario asegurar con certeza que ellos existían en el mundo "et ideo de hoc nulli dubium esse sed cum certitudine affirmare demones esse in mundo". ${ }^{36} \mathrm{El}$ énfasis en la obligación de creer en los demonios -como si se abrigara alguna duda, efectivamente- y la falacia sobre la cual se apoya la argumentación (es decir, un acuerdo entre las tres religiones del Libro, que dejaría fuera de cualquier ortodoxia a quien creyera lo contrario) resultan, como mínimo, sugerentes. La creencia en los demonios aparecía como una verdad de fe que debía ser reforzada.

Por otra parte, como ha indicado Yovel, el hincapié en la búsqueda de la salvación, noción tan vertebral en el cristianismo, era ajeno al judaísmo: "Desde luego -afirma el autor- que los judíos esperaban redimirse, pero la redención se entendía como un evento colectivo en el mundo inmanente que llevaría la existencia mundana a un punto culminante. Entrañaba, en esencia, la liberación de los judíos del dominio gentil, la restauración del tiempo y el gobierno de Dios desde Sión. Ni siquiera los místicos judíos (en la cábala), para quienes era un acontecimiento que afectaba al ser del universo entero, pensaban que la redención se centrase en la salvación del alma individual". ${ }^{37}$ Los judíos, más bien, anhelaban ganarse "su parte en el otro mundo" pero este deseo "no tenía el carácter de drama metafísico que el motivo de la salvación introducía en el cristianismo", con toda la parafernalia de la geografía ultramundana. Para los judíos, el otro mundo se parecía mucho más a una continuación, mejorada, de la existencia terrenal y accedían a él mediante la observación de la Ley y el cumplimiento de

33 Yovel, Y. 1989. Spinoza and Other Heretics (Vol I: The Marrano of Reason; Vol II: The adventures of Immanence). Princeton: Princeton Universtity Press. Edición en castellano: 1995. Spinoza, el marrano de la razón (trad. M. Cohen): 38-39. Madrid: Anaya \& Mario Muchnik.

34 Fortalitium fidei, Liber quintus, Consideratio I, f. 175r.

35 Respecto de la tradición musulmana en lo tocante al diablo, cf. Russell, J. 1984. Lucifer, the Devil in the Middle Ages. Ithaca: Cornell University Press. Cito por la siguiente edición castellana: 1995. Lucifer. El diablo en la Edad Media (trad. R. Salcedo): 55 y ss. Barcelona: Laertes.

36 Fortalitium fidei, Liber quintus, Consideratio I, f. $175 \mathrm{r}$.

37 Yovel, Y. 1995: 38 
los mandamientos. Dios estaba en forma inmanente en las leyes y los ritos de la Torá, lo cual, al decir de Yovel, "mitigaba su trascendencia, y los asuntos diarios y mundanos cobraban así una dimensión sagrada adicional". ${ }^{38}$

Entre las herejías que más preocupaban a fray Alonso, según se puede leer en el Liber secundus del Fortalitium, se encontraba la de aquellos que descreían de la resurrección, de la vida post mortem, de la existencia del cielo y el infierno e, incluso, de la mismísima existencia de Dios; otros descreían del purgatorio. ${ }^{39} \mathrm{~A}$ estas ideas que tanto inquietaban al fraile, Espina opone una demonología explícita y detallada, tratada en un liber particular, que permitía remarcar, a la vez, la existencia de un plano trascendente y la injerencia de dicho plano en la historia y el destino providencial de cada quien. En la consideración cuarta del Liber quintus, por ejemplo, Espina realza la existencia del trasmundo: sostiene que los demonios, hasta el día del Juicio, no tenían como morada el infierno sino el aire o la atmósfera tenebrosa, es decir, "el medio", donde se agitan los vientos y se originan las tempestades, desde donde podían tentar a los hombres cuando Dios se los permitía. Afirma, no obstante, que algunos demonios iban al infierno para "retorcer" las almas, siguiendo lo enseñado por Buenaventura ("bene credo quod aliqui descendunt illuc ad torquendas animas"). Lo mismo -añade el fraile- enseñaba el Maestro: "demones alternatis vicibus descendunt in infernum quare illuc animas detinent atque cruciant". ${ }^{40}$ Los demonios, protagonistas del infierno y agitadores de tormentas, tenían la doble función de intervenir en la Tierra desde el supramundo y, al hacerlo, argumentar en favor de la existencia de aquél y de la posibilidad misma de condena eterna. La pura "carnalidad", banalidad o inmanencia del pensamiento de todos aquellos que descreían de la existencia de más allá o del castigo de los pecados post mortem o, simplemente, de aquellos que hacían a un lado la moral cristiana en pos de beneficios mundanos era desmantelada, advertida e, incluso, amenazada por medio del despliegue mismo de la demonología cristiana.

Podríamos decir, en pocas palabras, que la demonología de Espina, con sus variados matices, reinsertaba los males que azotaban la Península, el deseo de salvación (tanto comunitaria como individual, como veremos a continuación) y el modo de alcanzarla dentro del drama metafísico cristiano. Si, en el caso de la llamada "demonología radical", la bruja hizo las veces de significante material de la divinidad, paliativo que -de acuerdo con la tesis de Stephens- venía a contrarrestar el temor a la inexistencia del orden de lo sobrenatural entre los teólogos mismos, en la demonología hispana del siglo XV el renovado énfasis en el discurso demonológico tradicional vino a dotar de significado trascendente, de un correlato metafísico, a significantes materiales: el judío, el musulmán, el judaizante, el hereje, el adivino. ${ }^{41}$ Las dudas no parecen ser tanto las del teólogo (en este caso, Espina) sino las promovidas por corrientes de ideas subalternas y

41 Véase Stephens, W. 2002. Demon lovers: Witchcraft, Sex and the Crisis of Belief, Chicago: University of Chicago Press.
}

heterodoxas, por prácticas poco comprometidas y vanas que Espina consideraba peligrosas para la fe, para la ecclesia y para el alma de los fieles.

\section{c. La guerra individual y la guerra colectiva. La reforma de la Iglesia in membris.}

Por otra parte, el discurso demonológico de Espina resultaba sumamente útil, en mi opinión, para ajustar otros dos planos imbricados en las luchas contra la fe descritas por el fraile: el plano colectivo y el plano individual, es decir, el de la ecclesia en su totalidad y el del alma de cada hombre. Al ser descritos los demonios como enemigos espirituales de esta última y, al mismo tiempo, como instigadores de los enemigos corporales de la sociedad cristiana toda, el discurso demonológico postulado por Espina permitía hacer hincapié en la doble dinámica envuelta en la macro-guerra descrita en el Fortalitium fidei y presentarla como dos caras de una misma moneda.

Como ha sostenido Vidal Doval, la alegoría de la fortaleza a la que recurre Espina para dar forma a su obra envolvía una multiplicidad de significados que el fraile no se esmeró en desambiguar. En opinión de la autora, el franciscano pudo haberse servido de esta imagen justamente porque estaba abierta a diversas interpretaciones. ${ }^{42}$ Y nuevamente Agustín es quien sienta antecedente al respecto: en Enarrationes in Psalmos (PL XXXVI, 67-1027 y XXXVII, 1033-1965), el Hiponense interpreta la fortaleza referida en el Salmo 61 como alegoría de la ecclesia y, también, como alegoría del alma. En principio, el castillo asediado es allí -como lo será en el Fortalitium - metáfora de la Iglesia militante, que es atacada por todos los flancos por sus enemigos (infieles, herejes), al tiempo que es representada como un castillo inexpugnable, es decir, que es también imagen de la Iglesia triunfante que, llegada la Parusía, prevalecerá y verá a sus enemigos derrotados. En este sentido, la fortaleza remarca, una vez más, el lazo antes visto entre la historia y la suprahistoria.

Ahora bien, para Agustín de Hipona, la fortaleza asediada no sólo era una alegoría de la ecclesia en su conjunto sino también, de modo simultáneo, representaba el alma humana del cristiano que era continuamente acosada por los vicios y la tentación del pecado. ${ }^{43}$ Este segundo sentido de la alegoría es también retomado por Espina y en ambas interpretaciones, el demonio desempeña un rol fundamental: tentando el alma del hombre de modo constante, engañándolo con farsas e ilusiones e, incluso, asediando su cuerpo, el demonio era artista exclusivo del ataque.

Esta imagen de fortaleza asediada y, a la vez, inexpugnable, tanto como el ambivalente juego entre castilloecclesia y castillo-alma resulta patente en la consideración novena del Liber quintus. Allí, el fraile sostiene que, para

42 Vidal Doval, R. 2005. "El muro en el Oeste y La fortaleza de la $\mathrm{Fe}$ : alegorías de la exclusión de minorías religiosas en la Castilla del siglo XV", en R. Sanmartín Bastida y R. Vidal Doval, Las metamorfosis de la alegoría: discurso y poder en la Península Ibérica desde la Edad Media hasta la Edad Contemporánea: 151-152. Frankfurt am Main: Vervuert; Madrid: Iberoamericana.

43 Ibídem: 153. 
comprender la guerra del demonio contra el hombre desde la venida de Cristo en adelante, cabía imaginar la ecclesia como una Ciudad de Dios llamada "Fortaleza de la fe", "Ciudad de la salvación" o "Ciudad de la buena conciencia". Tal ciudad estaba definida por doce perfecciones: su ubicación (en el centro, alejada de los extremos, es decir, de los vicios y los pecados), su belleza, su seguridad, su buena salud (ajena a la enfermedad del pecado), su amenidad, la buena disposición de su edificación, la concordia entre sus ciudadanos, la abundancia de privilegios, la prodigalidad de vituallas, su buen gobierno, su libertad respecto de la esclavización del demonio $y$, finalmente, su plenitud de amor y caridad. Esta Jerusalén descendida del cielo, ciudad tan perfecta, "esposa de Cristo", fue dotada -continúa Espinade tres resguardos fundamentales. En primer lugar, de un muro que era la caritas, que debía ser custodiado por los prelados de la Iglesia. Éstos, situados en la puerta de la ciudad, debían estar dispuestos a ofrecer la penitencia como remedio si acaso alguien retornara de la guerra del diablo malherido a causa del pecado. También debían estar allí para recibir a los pobres y ofrecerles los bienes de la Iglesia. En segundo lugar, Dios dispuso un antemural, que es la justicia y la equidad. El antemural debía ser defendido por los príncipes cristianos, cuyo deber era administrar justicia, según lo dispuesto en Sabiduría 1, 1. Debían estar atentos y resguardar la ciudad de cualquier enemigo que deseara atacar la muralla. Finalmente, la Ciudad fue dotada de un foso profundo: la humidad. Los religiosos eran quienes debían practicarla y enseñarla. ${ }^{44}$

Fray Alonso sostiene, luego, que el demonio se afligió profundamente ante tanta perfección, gloria y felicidad y al ver que muchas almas que allí habitaban, liberadas de la esclavitud diabólica, iban al cielo. Por este motivo -dice el fraile- el demonio dispuso una sucesión de ataques contra la fortaleza de la fe. En primer lugar, alentó la persecución de los cristianos en manos de los gentiles, durante más de doscientos años. Esta primera batalla la perdió el demonio: cientos de miles murieron, mártires, declarando la fe verdadera, lo que multiplicó la cantidad de fieles y fortaleció la Ciudad de la Justificación. Derrotado, el diablo estimuló una segunda guerra: la de los herejes. Muchos fueron quemados en la hoguera y sus doctrinas erróneas refutadas en sucesivos concilios. Si bien -dice Espina- los herejes se ensañaban subrepticiamente contra la ecclesia (como sostiene también en el Liber secundus), sus voces -agregano eran oídas públicamente. ${ }^{45}$ Por este motivo, el demonio decidió edificar una ciudad diabólica sobre el cimiento del desprecio de Dios, es decir, una ciudad de vicios opuesta a la urbe divina, llamada Babilonia, y dispuso allí doce abusos: príncipe injusto, cortesano adulador, soldado desleal, consejero esquivo de la verdad, magistrado sin piedad, prelado sin caridad, abogado de la rapacidad, clérigo ignorante, religioso soberbio, mercader falso, joven sin respeto y pueblo enemistado. Montó también tres defensas, opuestas a las antes mencionadas: una muralla de animosidad y división, un antemural de injusticia y opresión, un foso de soberbia

\footnotetext{
44 Fortalitium fidei, Liber quintus, Consideratio IX: f. 181v. 45 Ídem.
}

y ambición. ${ }^{46}$ Luego, viendo que Dios le daba permiso para expugnar la Ciudad de la Justificación, organizó su ejército en tres batallones de ataque: el primero, liderado por Satán, guerreó contra los religiosos que custodiaban el foso de la humildad, portando como armas la ambición y la arrogancia. El segundo, capitaneado por Belzebú, atacó el antemural de la justicia oponiéndole la opresión y la iniquidad. Luego, la tercera línea de combate era liderada por Mammón, quien asedió la muralla de la Ciudad de Dios con las fortísimas armas de la avaricia y la simonía. ${ }^{47}$ Es, pues, desde el pecado y la tentación, atacando el alma de los sujetos que habitaban la ciudad (prelados, príncipes, religiosos...), que el diablo socavaba la ecclesia en su conjunto.

Y -dice Espina- muchos cayeron heridos mortalmente por los ataques del demonio. Muchos religiosos, guardianes del foso, resultaron heridos y asesinados por la tropa de Satán, a causa de la soberbia: algunos por su simulada santidad ("qui ferunt habitum humilitatis in corpore et leonem superbie in corde"); ;8 otros, por su presunción y vana curiosidad, por las cuales caían en engaños del demonio, deseando tener visiones o revelaciones; otros, ambicionaban su propia gloria y honor; otros, vencidos, abandonaron incluso sus conventos para satisfacer la codicia. Luego, muchos príncipes, nobles y consejeros, custodios del antemural de la justicia, cayeron heridos de muerte por los diablos de Belzebú. Opresores de pueblos y de quienes no tenían poder, gobernaban como tiranos, con iniquidad. Finalmente, Mammón atacó con eficacia a muchos prelados que, debiendo proteger la muralla de la caridad, se dejaron vencer por la simonía, la avaricia, los favores ilícitos, el nepotismo: "non vigilant illi tales propter curam animarum sed bursarum". ${ }^{49}$

Ahora bien, estos ataques exitosos a las almas de los cristianos hicieron, en opinión de Espina, que la fortaleza en su conjunto estuviese prácticamente en su totalidad expugnada por los demonios. El fraile gime al ver cuán debilitado se hallaba el foso ("O quam debelitatum est fossatum civitatis Dei et quam pauci veri religiosi humiles reperiuntur in orbe, presertim cum multi cadunt ex simulata sanctitate"); $;^{50}$ cuán derrumbado el antemural ("Sic ergo antemurale civitatis iustificationis quasi totum videtur diruptum et expugnatum per demones" $)^{51}$ y cuán roto el muro, a tal punto que los demonios entraron a la Ciudad de la Santificación (ecclesia y alma) y conquistaron los pensamientos, las afecciones y el consentimiento de los hombres, de modo tal que muchos cayeron a las llamas del infierno y casi no quedaba de la urbe divina piedra sobre piedra:

Rupto ergo muro et peremptis talibus custodibus iniquis ex vulneribus avaricie et simonie, ingrediuntur demones civitatem sanctificationis et occidunt filios, scilicet, cogitaciones, eorum capiunt mulieres, scilicet, afectiones,

46 Ídem.

47 Ídem: "Cum ergo ex divina permissione vidit dyabolus se potentem ad expugnandum magna parte predictam civitatem, ordinavit exercitum suum in triplici acie. In prima posuit capitaneum Sathan, in secunda Beelzebub, in tercia vero Mammonam...".

48 Ídem.

49 Ídem.

50 Ibídem: f. 182 r.

51 Ibídem: f. $182 \mathrm{v}$. 
et viros, scilicet, consensus, quos captivos in dampnationem perpetuam abissi infernalis deducunt pro magna parte et civitatem ignibus exponunt, ut non remaneat lapis super lapidem, quare quasi nihil iusticie nihil humilitatis nihil caritatis remanet in illa civitate. ${ }^{52}$

La imagen de la fortaleza asediada convive y es superada, no obstante, por la noción de fortaleza inexpugnable. Si bien muchos religiosos, custodios del foso, habían perecido en manos del demonio, según Espina siempre permanecían firmes algunos, que resistían con valentía y defendían la ciudad amada ("licet innumeri cadant et pereant de fossato victi a dyabolo, aliqui tamen semper manent qui viriliter resistunt, quos Deus cognoscit et reservat pro defensione sue civitatis dilecte")..$^{53}$ Lo mismo sucedía con el antemural: si bien había muchísimos príncipes impíos, Dios reservaba a algunos en los cuales conservaba la verdad de la justificación ("aliquos Deus suo occulto iudicio semper reservet in quibus servetur veritas iustificationis")..$^{54}$ Finalmente, la caridad dice Espina- es fortísima y "nunca desaparece" (I Corintios 13), por lo cual el muro de la fe siempre perdura: si bien caían muchísimos religiosos, príncipes, prelados, eclesiásticos y súbditos, "semper tamen manent aliquij5 in quibus salvatur veritas fidei et iustificacio bone conscientie". Aunque sólo quedasen dos hombres fieles en el mundo -afirma el fraile-, en ellos se salvaría la ecclesia, que no es sino la unidad de los fieles, reunida por el vínculo de la caridad:

...secundum Crisostomum, iusti sunt in mundo sicut medula in arbore, qua deficiente deficit seu perit arbor. Ergo si non essent aliqui iusti periret mundus. Fluctuat ergo navicula Petri sed ${ }^{56}$ non mergitur bellorum turbinibus quibuscunque, quare porte inferi, id est demonum furie, non prevalebunt adversus eam cum sit turris fortitudinis a facie inimici. ${ }^{57}$

Esta doble interpretación de los ataques a la fortaleza de la fe como ataques in animam y ataques in ecclesiam, permite que el discurso de Espina adquiera características propias del discurso de un predicador: en numerosos pasajes del Fortalitium fidei, nuestro autor, como buen representante del franciscanismo reformado, aspira a lograr la reforma moral de los cristianos e incita en ellos la necesidad de conversión o reforzamiento de la fe. ${ }^{58}$ No casualmente Rucquoi escoge el discurso de Alonso de Espina como ejemplo paradigmático de "la mezcla de crítica social, diatribas en contra de los prelados ricos, largas digresiones sobre la vida

52 Ídem

53 Ibídem: f. 182 r.

54 Ibídem: f. 182v.

55 sic edd.; aliquibus ms.

56 sic edd.; si ms.

57 Fortalitium fidei, Liber quintus, Consideratio IX: f. 183r. El fraile incluye palabras de Mateo 16, 18 y del Psalmo 60, 4

58 El siglo XV estuvo signado por un movimiento de reforma dentro de la Orden franciscana en el reino de Castilla, de la cual Alonso de Espina tomó parte. Las transformaciones promovidas por la rama observante del franciscanismo no sólo aspiraban a lograr el cumplimiento intransigente de la Regla de San Francisco al interior de la orden sino también a incidir, con sus ideales y valores, en la sociedad en su conjunto (Rucquoi, A. 1996. "Los franciscanos en el reino de Castilla", en J. Iglesia Duarte et alii (coord.), VI Semana de Estudios Medievales: Nájera, 31 de julio al 4 de agosto de 1995: 65-86. Nájera: Instituto de Estudios Riojanos). y la Pasión de Cristo y profecías más o menos mesiánicas o milenaristas que alimentaba la predicación observante", que además, tal como hemos visto, "encontró a partir de mediados del siglo XV un nuevo blanco, los conversos". ${ }^{59}$

El valor catequístico y reformador de conciencias, el llamado a cuidar el alma, aparece en variadas ocasiones en el Fortalitium fidei, tratado que recoge en gran medida la experiencia de Espina como predicador e incorpora, por lo tanto, trazos del discurso homilético. Aparece con suma claridad, por ejemplo, al comienzo mismo del Liber primus, cuando Espina alienta a todos los fieles a utilizar como armadura espiritual, en defensa de los enemigos, la continencia, la virtud de la justicia, el ejemplo de los santos, la fe, la esperanza y la palabra de Dios. ${ }^{60}$ Luego, en el Liber tercius, reaparece la cuestión en el apartado en el cual el fraile enumera los signos de la proximidad del fin de los tiempos. Esto no es una casualidad: la espera de los últimos días era un aguijón para la promoción de la reforma moral. ${ }^{61} \mathrm{En}$ dicho apartado, el fraile no enumera aquellas señales que habían sido codificadas por una larga tradición apocalíptica cristiana, desarrollada a lo largo del período medieval, que consistían en prodigios naturales (a saber, que se levantaran las aguas del mar, que se prendieran fuego mares y ríos, que los árboles y plantas exudaran sangre, catástrofes climatológicas, que los peces dieran bramidos, etc.). ${ }^{62}$ Por el contrario, el franciscano enumera una sucesión de faltas morales que indicarían la próxima llegada del Apocalipsis, tales como la plétora de vicios (citando la carta a Timoteo, afirma que, en los últimos días, los hombres se amarán a sí mismos, serán blasfemos, desobedientes, ingratos, vivirán sin paz ni benignidad, etc.); ;3 la desaparición de toda autoridad espiritual y jurisdicción terrenal, por no tener en cuenta ningún rey ni profeta la verdad de la vida, la justicia y la doctrina; ${ }^{64}$ la duda en la fe y la multiplicación de los errores y engaños ("dubitatio in fide et pulullacio erroris et deceptionum"), etc. ${ }^{65}$ Tras catalogar diversos "signos" de este tipo de la proximidad del fin de los tiempos, Espina, insinuante, invita al lector a

59 Rucquoi, A. 1996: 84

60 Fortalitium fidei, Liber primus, Consideratio I, f. 11 r

61 Incluso la gran preocupación en relación a los judeoconversos puede leerse en esta misma lógica: "messianism led the Francisans to develop a particular type of approach to the problema of conversion. In contrast to the Dominicans, and later the Jesuits, who both favoured a "gradualist" approach to conversion, the Franciscans were much more confrontational" (McKendrick, G. 1988. The Franciscan Order in Castile, c. 1440-1560: 61. Edinburgh: University of Edinburgh).

62 Milhou, A. 1994. "Cristóbal Colón, iniciador de la visión escatológica del nuevo mundo en la literatura colonial", en P. Crovetto, Andando más más se sabe: atti del Convegno internazionale "La scoperta dell'America e la cultura italiana": Genova, 6-8 aprile 1992: 71-73. Roma: Bulzoni.

63 "Apostolus dicit secunda Thimo. tercio capitulo: "In novissimis temporibus, (...) erunt omnes se ipsos amantes, cupidi, elati, blasphemi, parentibus inobedientes, ingrati, (s)celesti, sine afectione, sine pace, criminatores, incontinentes, immites, sine benignitate, proditores, protervi, tumidi, voluptatum amatores magis quam Dei, habentes speciem quidem pietatis, virtutem eius abnegantes"(Fortalitium fidei, Liber tercius, Consideratio XII: f. 116r.).

64 Ídem: "In tempore illo non erit princeps, neque propheta, neque dux in populo meo, qui scilicet observet veritatem vite, iusticie et doctrine".

65 Fortalitium fidei, Liber tercius, Consideratio XII: f. 116v. 
evaluar si aquellos ya eran perceptibles en sus propios tiempos y a buscar refugio en Cristo, la fortaleza de la fe, con suma devoción. ${ }^{66}$ Cristo-fortaleza es, sin duda, el tercer sentido envuelto en la alegoría de la fortificación, tal vez el más perfecto: la torre, como ha señalado Vidal Doval, es también imagen topológica de Cristo. ${ }^{67}$

El signo reformador del discurso de Espina reaparece luego con particular claridad en el libro demonológico, quinto y último. El camino argumental al respecto resulta evidente: el peligro que representaba el demonio para todas las almas, incluso las de hombres santos y rectos en la fe, obligaba a los individuos a refugiarse en el seno de la ecclesia y a amoldar su comportamiento y su pensar a las exigencias de la ortodoxia y la ortopraxis. Espina, citando la epístola a los Efesios, incita a tomar "la armadura de Dios", la virtud, para resistir a los demonios hasta el Día del Juicio ("accipite armaturam Dei, scilicet, virtutum, ut predictum est, ut possitis resistere insultibus demonum in die mala, id est, in presenti vita, ubi iminet temptacionum pugna usque ad diem iudicii"). ${ }^{68}$

Vidal Doval, analizando el proemio del Fortalitium, encuentra en la relación entre ambas interpretaciones de la fortaleza, en tanto Iglesia y en tanto alma, el mensaje vehiculizado por la obra de Alonso de Espina: "Ia Iglesia, que por extensión es la sociedad cristiana en la Castilla de la segunda mitad del siglo XV, es atacada por sus enemigos -herejes, judíos, sarracenos y demonios-, y aunque estos ataques no pueden poner en peligro su existencia como institución, tienen poder para dañar a los individuos que la componen". ${ }^{69}$ La relación así establecida entre el asedio sufrido por la sociedad/ecclesia y los ataques sufridos por el sujeto es recíproca: la conducta individual pecaminosa o desviada de los cristianos era lo que permitía que los enemigos de la fe (herejes, judíos, sarracenos) dañaran la sociedad en su conjunto. Esto nota la autora al analizar, simplemente, el proemio del Fortalitium: allí afirma Espina que, si los clérigos caían en el pecado y no investigaban los errores de los herejes, o si los jueces erraban al no castigar los crímenes de los judíos y musulmanes contra los cristianos, entonces el conjunto de la sociedad se hallaba indefenso ante estos ataques. ${ }^{70} \mathrm{Y}$ no sólo los poderosos del reino debían mantenerse rectos para resistir al demonio. Como vimos, Espina afirma que los vicios de la ciudad diabólica afectaban a príncipes y prelados y, también, a consejeros, nobles, clérigos, comerciantes, jóvenes y, en pocas palabras, al pueblo todo, en sus distintos niveles, expugnado por el pecado.

El discurso demonológico resultaba provechoso a Espina, por lo tanto, para demostrar que el ataque de los enemigos de la fe no tenía sólo un nivel comunitario o social (en el cual el ganador estaba designado de antemano y era conocido) sino que había un riesgo real de que el alma de

66 Ídem: "Videat et contempletur diligens lector si forte mundum in presenti inveniat aliquibus de predictis signis vulneratum, et recurrat devotissime ad fortissimum defensorem Ihesum Christum, Dominum nostrum, qui est turris fortitudinis a facie inimici, cuius singulari presidio fides christianorum inviolabilis sine fine perseveret".

67 Vidal Doval, R. 2005: 154.

68 Fortalitium fidei, Liber quintus, Consideratio IX: f. 183r.

69 Vidal Doval, R. 2005: 154.

70 Fortalitium fidei, Prohemium: f. $9 \mathrm{v}$. cada cristiano se perdiera. En cualquier caso, lo interesante es que el mensaje de reforma social y renovación moral se vinculaba, en ambos casos, a los ataques del enemigo y quedaba articulado en torno de la misma figura alegórica: la fortaleza asediada por el demonio y por aquellos a los que él poseía "por pacífico derecho". ${ }^{71}$ La doble dimensión, individual y colectiva, que -sirviéndose de la demonologíaotorga Espina a las guerras que describe a lo largo de los folios del Fortalitium (guerras que, como vimos, reunían, a su vez, la historia y la suprahistoria, lo material y lo trascendente) se expresa con claridad en el pasaje en el cual el franciscano afirma que Dios asignaba un ángel bueno a toda ciudad $-\mathrm{y}$ a todo campamento- para que velara por los asuntos comunes y que los demonios situaban en cada ciudad un demonio para que los perturbara $y$, del mismo modo, Dios otorgaba a cada arzobispo, obispo y sacerdote de parroquia un ángel bueno que procuraba la salvación de sus almas mientras que los demonios les asignaban un diablo que las perturbara, "et quanto sanctior est persona, tanto potentior est dyabolus ei assignatus". ${ }^{72}$

Finalmente, cabe decir lo siguiente: el escenario de la lucha, la escala del ataque y el grado de peligrosidad e intensidad de la hostilidad que Espina otorgaba a cada uno de los colectivos combatidos en el Fortalitium fidei tenía, por supuesto, un correlato en el tipo de defensa que -según el fraile- era necesario oponerles y en las medidas que ante dichos enemigos demandaba y reivindicaba el franciscano. Como indica Meyuhas Ginio, "la lutte des chrétiens croyants contre les démons ne se déroule pas sur le plan de la polémique religieuse, ni, non plus, sur les champs de bataille. C'est un combat quotidien et sans trêve qui se déroule dans le coeur de l'homme".73 Una lucha semejante requería, pues, medidas especiales: mientras que Espina promovía Inquisición, expulsión y guerra contra herejes, judíos y sarracenos, contra los demonios los recaudos a tomar debían ser de una índole muy distinta. En opinión del fraile, los predicadores, "milites Christi", eran quienes, anunciando la palabra de Dios, vencían a los demonios: "predicatores vincunt diabolum, et sic (...) crudeliorem et forciorem, vincunt inimicum expellentes non solum de se sed etiam de cordibus audiencium". ${ }^{74}$ Asimismo, la malicia del diablo era combatida por la resistencia de los buenos espíritus (los ángeles custodios) y, también, por medio del libre arbitrio del hombre, cuando éste no consentía las tentaciones del demonio. ${ }^{75}$ Las virtudes de la Ciudad de Dios, por las cuales sus

71 Fortalitium fidei, Liber quintus, Consideratio IX: f. 181v.: “... iudeos, saracenos nec hereticos et alios obstinatos (...) quos quieto iure se possidere sentit".

72 Fortalitium fidei, Liber quintus, Consideratio V: f. 179r.: “....sicut cuilibet civitati et cuilibet castro prefigitur a Deo unus angelus bonus, de negociis comunibus curam habens quantum sibi possibile est, sic etiam cuilibet civitati et castro prefigitur a demonibus unus demon ad negocia comunia perturbanda quantum sibi possibile est. Sequitur etiam (...) quod sicut cuilibet archiepiscopo et episcopo et sacerdoti parrochiali prefigitur a Deo unus angelus bonus, curam habens de negociis ad salutem animarum pertinentibus, sic cuilibet predictorum prefigitur a demonibus unus demon, curam habens de perturbacione salutis animarum".

73 Meyuhas Ginio, A. 1998: 169.

74 Fortalitium fidei, Liber primus, Consideratio II: f. 13v.

75 Fortalitium fidei, Liber quintus, Consideratio VIII: f. 181r. 
muros se tornaban imbatibles ante el diablo, eran -según Espina- la buena consciencia, la seguridad que no temía ante las adversidades, la gracia abundante y la caridad. El foso profundo que rodeaba y protegía del ataque de los demonios a la Ciudad de la Justificación era la humildad y la medicina que sanaba las heridas infringidas por los demonios era la penitencia. ${ }^{76}$ Este llamado a entablar una lucha de carácter interno o espiritual contra el demonio comprometía fuertemente, como resulta evidente, el plano de la moralidad.

\section{CONCLUSIÓN}

Hemos visto hasta aquí diversas cuestiones envueltas en el discurso sobre el demonio que despliega Alonso de Espina en el Fortalitium fidei. Vimos que, aun dejando de lado la novedosa "demonología radical" que comenzó a forjarse en la década de 1430 en otros sitios de Europa (a la cual Espina, escéptico respecto de la realidad del aquelarre nocturno, no adhiere), la alarma ante la proximidad del fin del mundo y el "último furor de Satánas" anunciado en las Escrituras (Apocalipsis 12, 12) se expresó en Castilla de un modo acorde a las inquietudes, la coyuntura y la historia propias de este ámbito cultural.

Sin duda, como bien han indicado Pereda y de Carlos, la "función ideológica" que cumple el discurso sobre el demonio en el Fortalitium fidei era, fundamentalmente, "la de descubrir la mano del diablo detrás de cada uno de los enemigos que amenazan a la Iglesia". ${ }^{77} \mathrm{Y}$ esos enemigos no eran las brujas en el terruño castellano sino, fundamentalmente, judíos y herejes. Una de las ilustraciones que acompañan el manuscrito del Fortalitium fidei conservado en la biblioteca capitular del Burgo de Osma, que antecede al inicio del Liber primus, da cuenta palmariamente del lazo directo que el tratado de Espina establece entre los ángeles malignos y los enemigos terrenales de la fe. En la imagen, los milites christiani luchan contra el ejército de sarracenos y demonios que atacaba la fortaleza de la fe. Ésta no sólo es custodiada por las huestes cristianas sino también por los ángeles de Dios. Asimismo, el castillo aparece socavado en sus propios cimientos por los herejes, al costado izquierdo de la imagen; del lado derecho, por su parte, los judíos son representados encadenados al suelo, con los ojos vendados. Lo que resulta particularmente sugerente es que, a ambos lados de la imagen, han sido dibujados dos demonios: en el margen izquierdo, uno sosteniendo una leyenda que reza claramente "mihi sunt heretici"; en el margen derecho, otro portando un letrero en donde se lee "mihi sunt iudei". ${ }^{78} \mathrm{El}$ dativo posesivo, en ambos casos, remarca que judíos y herejes pertenecían a los demonios, formaban parte de la lucha diabólica contra la ecclesia.

El presente trabajo, ahondando más en esta "función ideológica" clave de la demonología de Espina, resalta la significación concreta que adquiere el Liber quintus en relación con inquietudes fundamentales que expresa fray Alonso a lo largo del Fortalitium. Su demonología, en efecto, le resultaba útil no sólo para ligar con el diablo a los enemigos de la fe sino también para refutar las heterodoxias y descreencias más peligrosas que dichos enemigos portaban consigo. Permitía hacer hincapié en el lazo existente entre el mundo sensible y el suprasensible ante todos aquellos que descreían del más allá -e, incluso, de la divinidad-, recordando la importancia y la enorme injerencia del plano trascendente en el devenir de la historia y en el destino de la cristiandad, tanto a nivel individual como comunitario. Las formulaciones demonológicas de Espina, en este mismo sentido, incitaban a la conversión a la fe con dramatismo, alentaban la reforma de costumbres y el reforzamiento de la moralidad en un reino que el fraile veía asolado no sólo por los infieles sino, también, por los vicios.
76 Fortalitium fidei, Liber quintus, Consideratio IX: f. 181v.

77 Pereda, F. y de Carlos, M. 2004. “Desalmados: imágenes del demonio en la cultura visual de Castilla, siglos XIII-XVII. Un itinerario", en M. Tausiet y J. Amelang (eds.), El diablo en la Edad Moderna: 240. Madrid: Marcial Pons.
78 Fortalitium fidei: f. 10v. 


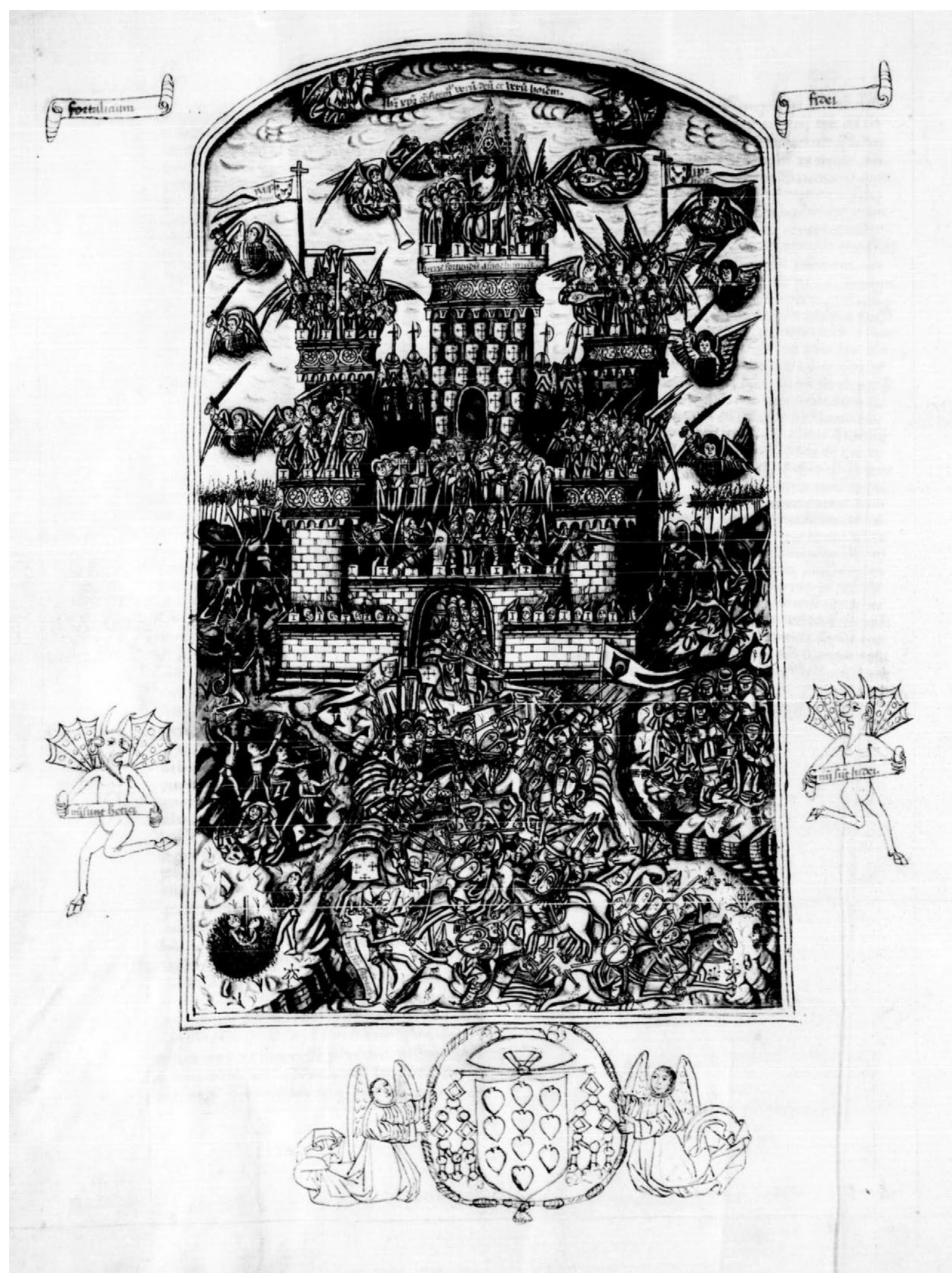




\section{BiBLIOgRAFÍA}

Alcoberro, A. 2014. "The Catalan Church and the Witch Hunt: the Royal Survey of 1621". eHumanista. Journal of Iberian Studies 26: 153-169.

Arlés y Andosilla, M., De superstitionibus, en G. Gaztambide, 1971. "El tratado 'De superstitionibus' de Martín de Andosilla". Cuadernos de Etnología y Etnografía de Navarra III: 249-322.

Azurmendi, M. 2013. Las brujas de Zugarramurdi. La historia del aquelarre y la Inquisición. Córdoba: Almuzara.

Basín, B. 1483. Tractatus exquissitimus de magicis artibus et magorum maleficiis, París.

Basín, B. 1988. "Tratado notable de las artes mágicas y maleficios de los magos", en M. Jiménez Monteserín (ed.), "De brujos y teólogos. Cultura popular y mundo mágico". Áreas 9: 170-182.

Bazán Díaz, I. 2014. "El tratado de Fray Martín de Castañega como remedio contra la superstición y la brujería en la diócesis de Calahorra y La Calzada: ¿un discurso al margen del contexto histórico (1441-1529)?". eHumanista. Journal of Iberian Studies 26:18-53.

Benjamin, W. 1971. Zur Kritik der Gewalt und andere Aufsätze. Frankfurt am Main: Suhrkamp. Edición en castellano: 1978. Para una crítica de la violencia (trad. M. A. Sandoval). México: Premiá.

Boureau, A. 1993. L'événement sans fin. Récit et christianisme au Moyen Age. Paris: Les Belles Lettres.

Campagne, F. 2002. Homo catholicus. Homo superstitiosus. El discurso antisupersticioso en la España de los siglos XV a XVIII. Madrid: Miño y Dávila.

Castell Granados, P. 2014. "Wine vat witches suffocate children. The Mythical Components of the Iberian Witch". eHumanista. Journal of Iberian Studies 26: 170-195.

Cavallero, C. 2011. "Brujería, superstición y 'cuestión conversa'. Historias de construcción de 'otros-cristianos'”. Anuario de Estudios Medievales 41,1: 343-373.

Cavallero, C. 2012. “A facie inimici: la dimensión política de la demonología cristiana en el Fortalitium Fidei de Alonso de Espina (Castilla, siglo xv)". Edad Media. Revista de Historia 13: 209-239.

Cavallero, C. 2013. "Judíos, conversos y "malos cristianos" en el Fortalitium fidei de Alonso de Espina: la mirada del Cíclope ante una encrucijada decisiva (Castilla, siglo Xv)", en F. Campagne (ed.), Poder y religión en el mundo moderno. La cultura como escenario del conflicto en la Europa de los siglos XV a XVIII: 117-162. Buenos Aires: Biblos.

Cavallero, C. 2014. "En los confines del relato cristiano: los pliegues del antijudaísmo en el Fortalitium fidei de Alonso de Espina (Castilla, siglo xv)", en A. Guiance (ed.), Legendario cristiano: creencias y espiritualidad en el pensamiento medieval: 53-101. Buenos Aires: CONICET - Instituto Multidisciplinario de Historia y Ciencias Humanas.

Clark, S. 2001. "Brujería e imaginación histórica. Nuevas interpretaciones de la demonología en la Edad Moderna" en
M. Tausiet y J. Amelang (eds.), El diablo en la Edad Moderna: 21-44. Madrid: Marcial Pons.

Congar, Y. 1968. L'ecclésiologie du haut Moyen Age. Paris: Éd. du Cerf.

Delumeau, J. 1978. La Peur en Occidente aux XIV et XVIII siècles. Une cité assiégée. Paris: Fayard. Edición castellana: 2002. El miedo en Occidente (Siglos XIV-XVIII). Una ciudad sitiada (trad. M. Armiño). Madrid: Taurus.

Echevarría, A. 1999. The fortress of faith: the attitude towards Muslims in fifteenth century Spain, Leiden-BostonKoln: Brill.

Espina, A. 1464. Fortalitium fidei. Archivo de la Catedral de El Burgo de Osma, cód. 154.

Espina, A. 1471. Fortalitium fidei. Strasbourg: Ed. Johannes Mentelin.

Espina, A. 1485. Fortalitium fidei. Nuremberg: Ed. Antonius Koberger.

Espina, A. 1487. Fortalitium fidei. Lyon: Ed. Guillelmus Balsarin.

Espina, A. 1494. Fortalitium fidei. Nuremberg: Ed. Antonius Koberger.

Espina, A. 1511. Fortalitium fidei. Lyon: Ed. Johannes de Romoys.

Espina, A. 1525. Fortalitium fidei. Paris: Ed. Johannes Moyli.

Fernández de Madrigal, A. 1507. Commentaria super Genesim. Venetiis.

Fernández de Madrigal, A. 1506. In quinquem prima capitula beati Matthei explanatio. Venetiis.

Haliczer, S. 1991. "The Jew As Witch: Displaced Aggression and the Myth of the Santo Niño de La Guardia", en M. Perry y A. Cruz (eds.), Cultural Encounters. The Impact of the Inquisition in Spain and the New World: 146-156. Berkeley: University of California Press.

Henningsen, G. 2003. "La Inquisición y las brujas", en A. Borromeo (ed.), L'Inquisizione, atti del Simposio internazionale Citta del Vaticano, 29-31 ottobre 1998: 567-605. Citta del Vaticano: Biblioteca Apostólica Vaticana.

Kamen, H. 2006. "Spain”, en R. Golden (ed.), Encyclopedia of witchcraft: the Western tradition: 1069-1070. Santa Barbara: ABC-Clío.

Knutsen, G. 2010. Servants of Satan and masters of demons: The Spanish Inquisition's Trials for Superstition, Valencia and Barcelona, 1478-1700. Turnhout: Brepols.

Kramer, H. y Sprenger, J. 2006. Malleus maléficarum. EI martillo de los brujos. El libro infame de la Inquisición (trad. Del inglés E. D'Elio). Barcelona-México: Reditar.

Levack, B. 1995. The Witch-Hunt in Early Modern Europe. London: Longman. Edición castellana: 1995. La caza de brujas en la Europa moderna (trad. J. Aristu). Madrid: Alianza.

Lope de Barrientos, 2000. Tratado de Caso y Fortuna, Tratado del Dormir y Despertar y Tratado de las especies de adivinanzas, en F. Álvarez López, Arte mágica y hechicería medieval. Tres tratados de magia en la corte de Juan II. Valladolid: Diputación de Valladolid. 
Madrigal Terrazas, S. 2000. El proyecto eclesiológico de Juan de Segovia (1393-1458). Estudio del Liber de substantia ecclesiae. Edición y selección de textos. Madrid: Universidad Pontificia Comillas.

Mann, J. 1996, "The Devilish Pope: Eugenius IV as Lucifer in the Later Works of Juan de Segovia". Church History 65, 2: 184-196.

Martin, R. 1989. Witchcraft and the Inquisition in Venice, 1550-1650. Nueva York-Oxford: Blackwell.

Mates, R. 1991. La razón de los vencidos. Barcelona: Anthropos.

McKendrick, G. 1988. The Franciscan Order in Castile, c. 1440-1560. Edinburgh: University of Edinburgh.

McMichael, S. 2007. "Friar Alonso de Espina, Prayer, and Medieval Jewish, Muslim and Christian Polemical Literature", en T. Johnson (ed.). Franciscans at Prayer: 271304. Leiden-Boston: Brill.

Meyuhas Ginio, A. 1998. La forteresse de la foi. La vision du monde d'Alonso de Espina, moine espagnol (?-1466). Paris: Cerf.

Meyuhas Ginio, A. 1990. "The conversos and the magic arts in Alonso de Espina's Fortalitium Fidei". Mediterranean Historical Review 5, 2: 169-182.

Milhou, A. 1994. "Cristóbal Colón, iniciador de la visión escatológica del nuevo mundo en la literatura colonial”, en P. Crovetto, Andando más más se sabe: atti del Convegno internazionale "La scoperta dell'America e la cultura italiana": Genova, 6-8 aprile 1992: 69-78. Roma: Bulzoni.

Monsalvo Antón, J. M. 2013. "Ideología y anfibología antijudías en la obra Fortalitium Fidei de Alonso de Espina. Un apunte metodológico", en P. de la Cruz Díaz Corral et alii. (eds.). El historiador y la sociedad: homenaje al profesor José María Mínguez: 163-188.Salamanca: Ediciones Universidad de Salamanca.

Monter, E. W. 1983. Ritual, Myth and Magic in Early Modern Europe. Brighton: Harvester Press.

Monter, E. W. 2013. "Witchcraft in Iberia", en B. Levack (ed.), The Oxford Handbook of Witchcraft in Early Modern Europe and Colonial America: 268-282. Oxford: Oxford University Press.

Muchembled, R. 2006. "Foreword", en R. Golden (ed.), Encyclopedia of witchcraft: the Western tradition: XXV-XXIX. Santa Barbara: ABC-Clío.
Nider, J. 2005. Les sorciers et leurs tromperies (La fourmilière, livre V). Grenoble: J. Million.

Pereda, F. y de Carlos, M. 2004. “Desalmados: imágenes del demonio en la cultura visual de Castilla, siglos XIII-XVII. Un itinerario", en M. Tausiet y J. Amelang (eds.), El diablo en la Edad Moderna: 233-252. Madrid: Marcial Pons.

Pérez, J. 2010. Historia de la brujería en España. Madrid: Espasa.

Rucquoi, A. 1996. "Los franciscanos en el reino de Castilla", en J. Iglesia Duarte et alii (coord.), VI Semana de Estudios Medievales: Nájera, 31 de julio al 4 de agosto de 1995: 65-86. Nájera: Instituto de Estudios Riojanos.

Russell, J. 1984. Lucifer, the Devil in the Middle Ages. Ithaca: Cornell University Press. Edición en castellano: 1995. Lucifer. El diablo en la Edad Media (trad. R. Salcedo). Barcelona: Laertes.

Stephens, W. 2002. Demon lovers: Witchcraft, Sex and the Crisis of Belief, Chicago: University of Chicago Press.

Trevor-Roper, H. 1969. The European Witch-Craze of the Sixteenth and Seventeenth Centuries, and Other Essays. New York: Harper \& Row. Edición castellana: 2009. La crisis del siglo XVII. Religión, Reforma y cambio social. Buenos Aires: Katz.

Verdon, J. 2008. Les superstitions. Paris: Perrin.

Vidal Doval, R. 2005. "El muro en el Oeste y La fortaleza de la Fe: alegorías de la exclusión de minorías religiosas en la Castilla del siglo XV", en R. Sanmartín Bastida y R. Vidal Doval, Las metamorfosis de la alegoría: discurso y poder en la Península Ibérica desde la Edad Media hasta la Edad Contemporánea: 143-168. Frankfurt am Main: Vervuert; Madrid: Iberoamericana.

Vidal Doval, R. 2013. Misera Hispania: Jews and Conversos in Alonso de Espina's Fortalitium fidei. Oxford: The Society for the Study of Medieval Languages and Literature.

Wolf, A. M. 2014. Juan de Segovia and the Fight for Peace. Christians and Muslims in the Fifteenth Century. Notre Dame: University of Notre Dame Press.

Yovel, Y. 1989. Spinoza and Other Heretics (Vol I: The Marrano of Reason; Vol II: The adventures of Immanence). Princeton: Princeton Universtity Press. Edición en castellano: 1995. Spinoza, el marrano de la razón (trad. M. Cohen). Madrid: Anaya \& Mario Muchnik. 